\title{
Using Physical Similarity Comminution and Sublimation Processes to Determine Energy Efficiency of Comminution
}

\author{
H. Otwinowski ${ }^{a, *}$, V.P. Zhukov ${ }^{b}$, T. WYleciat ${ }^{a}$, \\ A.N. BELYAKOV ${ }^{b}$ AND D. URBANIAK ${ }^{a}$ \\ ${ }^{a}$ Częstochowa University of Technology, ul. J.H. Dabrowskiego 69, 42-201 Częstochowa, Poland \\ ${ }^{b}$ Ivanovo State Power Engineering University, 153003 Ivanovo, Russia \\ Doi: 10.12693/APhysPolA.138.163 \\ *e-mail: otwinowski@imc.pcz.pl
}

\begin{abstract}
Estimating the energy efficiency of the comminution process regards a limited range of particle size classes and limited type of comminution equipment. On the basis of the proposed physical analogy between the comminution and sublimation processes, a universal criterion for the energy efficiency of the comminution process was developed. Description of the comminution process and estimation of its energy is based on a phenomenological approach, using the fundamental thermodynamic characteristics of the fed materials and the Rittinger hypothesis of comminution. This description was used to analyze the energy efficiency during the comminution process of various materials conducted in different types of mills, both laboratory and industrial ones. Introduced methodology can be used to compare the comminution process of materials with different particle composition in different types of equipment.

topics: physical similarity, comminution, sublimation, energy efficiency of comminution, degree of comminution, particle size distribution, Rittinger hypothesis, milling devices
\end{abstract}

\section{Introduction}

Granular materials used in many industries are obtained in the process of crushing mineral resources in various types of milling equipment. Due to the high complexity of the phenomena and energy consumption of the comminution process, a universal theory that would enable the formulation of a proper description of the comminution process has been sought for many years. This description should take into account energy consumption, which depends, among others, on the properties and degree of fragmentation of the feed, as well as the type and operational parameters of the mills used. Currently used comminution theories describe the course of the process of comminution various materials in various milling devices, but there is no comparative criterion that would allow the assessment and optimization of various processes.

The article presents a description of the kinetics of the comminution process, which is based on the physical analogy between comminution and sublimation processes [1-3]. On the basis of this analogy, a universal criterion for assessing the energy efficiency of comminution has been developed. The introduced methodology has been used to analyze the energy efficiency during the comminution process of various materials conducted in different types of mills (both laboratory and industrial ones).

\section{Methodology for determining energy efficiency of comminution process}

The sublimation process is considered to be physically similar to the comminution process. In the sublimation process, as in comminution, the breaking of intermolecular bonds occurs, generated by the energy supply. The thermodynamic characteristic of the sublimation process [3] is the specific heat of sublimation. It is obvious that the heat of sublimation represents the value of energy necessary to break all the intermolecular bonds in a unit of mass of a solid. In thermodynamics, the amount of energy consumed for transition to the gaseous state is determined by the difference in enthalpy of the system at the beginning and end of the process [3]. To describe the state of the system in the comminution process, a degree of comminution $x$ has been introduced, which is defined as the ratio of the average particle size of the feed to the average particle size of the product. For comminuted grains with a needle shape and size $d_{0}$, the degree of comminution can be represented in the following form:

$$
x=\frac{d_{0}}{\bar{d}}
$$

where $\bar{d}$ is average particle size of the product, which is calculated as the logarithmic mean of class sizes.

Given the proposed analogy between comminution and sublimation processes, the relationship 
between the comminution energy and comminution degree can be presented in accordance with the known thermodynamic relationship for phase transition energy in the form [3]:

$$
\Delta h=r_{s} \Delta x=r_{s}\left(x^{\prime \prime}-x^{\prime}\right),
$$

where $\Delta h$ is specific enthalpy or specific comminution energy, $r_{s}$ - specific heat of sublimation, $x^{\prime}, x^{\prime \prime}$ - degree of powder comminution before and after fragmentation, respectively.

The known dependence of the supplied energy on time, taking into account (2), allows the kinetics of the comminution process to be described with the following relationship:

$$
x^{\prime \prime}(t)=x^{\prime}+\Delta h(t) / r_{s} .
$$

Substituting the expression for the degree of comminution (1) in formula (2), we obtain the dependence of comminution energy on the average particle size

$$
\Delta h=r_{s} d_{0}\left(\frac{1}{\bar{d}^{\prime \prime}}-\frac{1}{\bar{d}^{\prime}}\right),
$$

where $\bar{d}^{\prime}, \bar{d}^{\prime \prime}$ is average particle size of the product before and after fragmentation, respectively.

The presented thermodynamic description of the comminution process (4) coincides with the well-known Rittinger energy theory of comminution [4-6]. The proportionality coefficient in the Rittinger theory, generally determined on the basis of experimental data, can be expressed taking into account (4) by the specific heat of sublimation

$$
c_{R}=r_{s} d_{0}
$$

where $c_{R}$ is proportionality coefficient in the Rittinger theory.

As a criterion for the energy efficiency of the comminution process, using the energy ratio which is theoretically necessary for comminution to the energy consumed for comminution, is proposed

$$
\eta=\frac{N_{t}}{N_{c}}=B r_{s} d_{0}\left(\frac{1}{\bar{d}^{\prime \prime}}-\frac{1}{\bar{d}^{\prime}}\right),
$$

where $N_{t}$ is theoretical energy for comminution process, $N_{c}$ - consumed energy for comminution process, $B-$ mill capacity.
The theoretical comminution energy is determined on the basis of Eq. (4). The value of consumed energy is determined on the basis of literature sources or based on the results of experimental research.

\section{Analysis of the energy efficiency of comminution in various milling devices}

The developed methodology was used to assess the energy efficiency of grinding anthracite, graphite and Dead Sea salt in a laboratory crusher (Fig. 1) [7], hammer crusher, centrifugal mill and ball mill [8-12]. The results of the calculations are presented in Fig. 2 (anthracite grinding in the laboratory crusher) and in Tables I and II. Calculations for pin, hammer and ball mills were carried out for a given value of consumed energy. The low absolute value of energy efficiency should be noted. This demonstrates significant reserves of the grinding process. Analysis of the obtained results showed that the most effective fragmentation at the maximum value of energy efficiency was achieved in the case of the laboratory crusher. This is related to the most effective use of supplied energy and sufficiently accurate determination of the consumed energy.
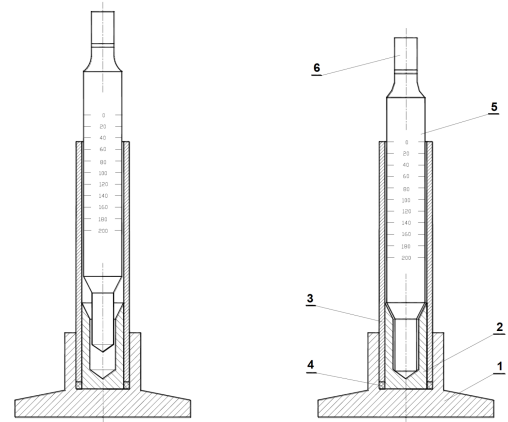

Fig. 1. Schematic of the laboratory crusher: 1 base, 2 - crushing chamber, 3 - guide cylinder, 4 - adjustment ring, 5 - swingle, 6 - additional weight.

TABLE I

The results of experimental studies on the grinding of the anthracite grains with sizes from $(1.6,2.0)[\mathrm{mm}]$ using the laboratory crusher for different values of supplied energy for the grinding process. $d$ is class size.

\begin{tabular}{c|c|c|c|c|c|c|c}
\hline \hline \multirow{2}{*}{$d[\mathrm{~mm}]$} & \multicolumn{7}{|c}{ Cumulative particle size distribution of ground material for different values } \\
& \multicolumn{7}{|c|}{ of supplied energy $e[\mathrm{~J} / \mathrm{kg}]$} \\
\cline { 2 - 8 } & 1420 & 1600 & 1950 & 2600 & 3030 & 3600 & 5180 \\
\hline 0 & 0 & 0 & 0 & 0 & 0 & 0 & 0 \\
0.16 & 0.0083 & 0.0150 & 0.0306 & 0.0643 & 0.0885 & 0.1244 & 0.2163 \\
0.40 & 0.0104 & 0.0293 & 0.1078 & 0.1514 & 0.1911 & 0.2484 & 0.3766 \\
0.63 & 0.0488 & 0.1106 & 0.1991 & 0.2909 & 0.3597 & 0.4395 & 0.6041 \\
1.00 & 0.0812 & 0.1789 & 0.3060 & 0.4492 & 0.5269 & 0.6187 & 0.7371 \\
1.25 & 0.1179 & 0.2285 & 0.3767 & 0.5170 & 0.6158 & 0.7342 & 0.8455 \\
1.60 & 0.3692 & 0.4507 & 0.5174 & 0.7189 & 0.7876 & 0.9150 & 0.9668 \\
2.00 & 1.0000 & 1.0000 & 1.0000 & 1.0000 & 1.0000 & 1.0000 & 1.0000
\end{tabular}


TABLE II

Comparison of energy comminution efficiency of various materials in different milling devices.

\begin{tabular}{l|c|c|c|c}
\hline \hline \multicolumn{1}{c|}{$\begin{array}{c}\text { Milling device } \\
\text { (fed material) }\end{array}$} & $\begin{array}{c}\bar{d}^{\prime} \\
{[\mathrm{mm}]}\end{array}$ & $\begin{array}{c}\bar{d}^{\prime \prime} \\
{[\mathrm{mm}]}\end{array}$ & $\begin{array}{c}e \\
{[\mathrm{~kJ} / \mathrm{kg}]}\end{array}$ & $\begin{array}{c}\eta \\
{[\%]}\end{array}$ \\
\hline $\begin{array}{l}\text { laboratory crusher } \\
\text { (anthracite) }\end{array}$ & 1.8 & $0.3-0.8$ & $1.42-5.18$ & 0.7171 \\
\hline $\begin{array}{l}\text { pin mill } n=6000 \mathrm{~min}^{-1} \\
\text { (salt) }\end{array}$ & 2.3 & 0.215 & 8.125 & 0.0519 \\
\hline $\begin{array}{l}\text { pin mill } n=10000 \mathrm{~min}^{-1} \\
\text { (salt) }\end{array}$ & 2.3 & 0.84 & 1.238 & 0.0611 \\
\hline $\begin{array}{l}\text { hammer mill } \\
\text { (salt) }\end{array}$ & 2.3 & 0.38 & 2.722 & 0.0807 \\
\hline $\begin{array}{l}\text { ball drum mill } \\
\text { (anthracite) }\end{array}$ & 10.0 & 0.1 & 127.12 & 0.0699
\end{tabular}

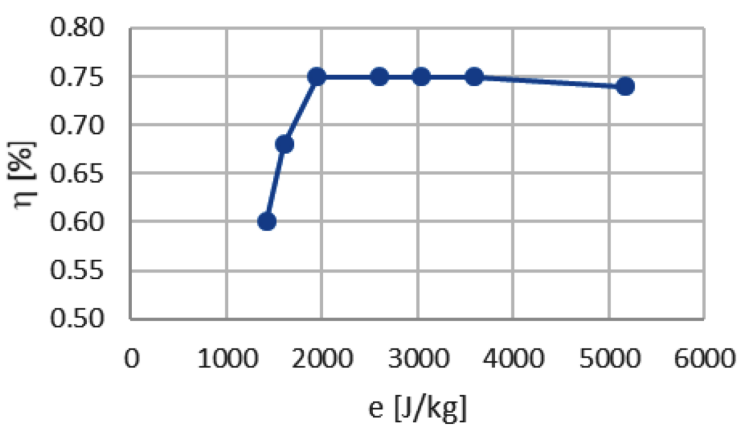

Fig. 2. Dependence of the energy efficiency of the anthracite comminution on the specific supplied energy in the laboratory crusher.

\section{Conclusions}

The analysis showed that the introduced energy efficiency coefficient allows, based on the basic thermodynamic properties of the substance, to compare the efficiency of comminution various materials in different mills. The proposed methodology makes it possible to assess the effectiveness of comminution of various materials in different types of milling devices.

\section{References}

[1] A.N. Belyakov, V.P. Zhukov, Vestnik Ivanovo State Power Eng. Univ. 1, 74 (2013) (in Russian).

[2] B.M. Jaworski, A.A. Dietłaf, Physics. Encyclopedic Guide, Wyd. Naukowe PWN, Warszawa 2004 (in Polish).

[3] S. Wiśniewski, Technical Thermodynamics, Wyd. WNT, Warszawa 2019 (in Polish).

[4] V. Mizonov, V. Zhukov, S. Bernotat, Simulation of Grinding: New Approaches, ISPEU Press, Ivanovo 1997.

[5] J. Zawada, Introduction to the Mechanics of Crushing Processes, Wyd. Instytutu Technologii Eksploatacji, Radom 1998 (in Polish).

[6] H. Otwinowski, Mechanical Processing of Mineral Raw Materials. Jet Comminution and Pneumatic Classification, Wyd. Politechniki Częstochowskiej, Częstochowa 2013 (in Polish).

[7] H. Otwinowski, Informational Theory in the Modelling of Comminution Process, Wyd. AGH, Kraków 2003 (in Polish).

[8] Guide to Ore Dressing. Preparatory Processes, Ed. O.S. Bogdanov, Nedra, Moskva 1982 (in Russian).

[9] A.N. Lebiediev, Dust Preparation in Power Plants, Gosenergoizdat, Moskva 1949 (in Russian).

[10] L.A. Letin, K.F. Roddatis, Medium and Low Speed Mills, Energoizdat, Moskva 1981 (in Russian).

[11] Y. Rozenblat, D. Portnikov, A. Levy, H. Kalman, S. Aman, J. Tomas, Powder Technol. 208, 215 (2011).

[12] D. Portnikov, H. Kalman, S. Aman, J. Tomas, Powder Technol. 237, 489 (2013). 